\title{
Evolution of Grain Boundary Phases during the Homogenization of AA7020 Aluminum Alloy
}

\begin{abstract}
A.R. EIVANI, H. AHMED, J. ZHOU, and J. DUSZCZYK
The presence of large constitutive particles formed during solidification decreases the strength and hot workability of aluminum alloys especially when they are located in the grain boundary (GB) regions. Therefore, the evolution of these phases is a major issue in the homogenization process of these alloys. There is a lack of information on the behavior of the GB phases during homogenization, which constitute more than 70 pct of all the secondary phases present in the microstructure of AA7020 aluminum alloys. The dominant GB phase is identified to be $\mathrm{Al}_{17}\left(\mathrm{Fe}_{3.2} \mathrm{Mn}_{0.8}\right) \mathrm{Si}_{2}$. In the present research, a comprehensive study on the effect of the homogenization treatment on the evolution of the GB phases during homogenization was conducted. The analysis shows that the evolution of this phase is largely dependent on temperature, which ranges from spheroidization with insignificant dissolution at low temperatures to full dissolution during homogenization at high temperatures. A new mechanism for the dissolution of these phases called thinning, discontinuation, and full dissolution (TDFD) is proposed based on the findings of the field emission gun-scanning electron microscope (FEG-SEM) analysis.
\end{abstract}

DOI: $10.1007 / \mathrm{s} 11661-008-9741-9$

(C) The Author(s) 2009. This article is published with open access at Springerlink.com

\section{INTRODUCTION}

THE mechanical properties of aluminum alloys are largely dependent on alloying elements present in solid solution. These elements increase the strength mainly through solid solution or precipitation hardening. ${ }^{[1]}$ During casting of aluminum alloys, a large fraction of alloying elements segregate to the liquid and form constitutive particles in the grain boundary $(\mathrm{GB})$ regions or inside the grains. ${ }^{[2]}$ These particles decrease the hot workability and, therefore, limit the range of process parameters applicable during subsequent extrusion ${ }^{[3]}$ It is well known that coarse residual particles $(>1 \mu \mathrm{m})$ deteriorate the extrudability of these alloys especially when they are located in the GB regions. ${ }^{[4-9]}$ Therefore, it is necessary to dissolve these particles in the structure in order to attain high mechanical properties and extrudability.

Although there have been a number of investigations on the homogenization treatments of aluminum alloys in recent years, ${ }^{[10-20]}$ most of the efforts have been focused on the nature and evolution of the $\mathrm{Al}_{2} \mathrm{Mg}_{3} \mathrm{Zn}_{3}$ (T), $\mathrm{Al}_{2} \mathrm{CuMg}(\mathrm{S}),(\mathrm{CuZnAl})_{2} \mathrm{Mg}$, and $\mathrm{MgZn}_{2}(\eta)$ phases ${ }^{[10-13]}$ and the formation and distribution of dispersoids ${ }^{[14-20]}$ during homogenization. In addition, in comparison with other aluminum alloys, the information on the 7XXX

A.R. EIVANI, PhD Researcher, and H. AHMED, Postdoctoral Researcher, are with the Materials Innovation Institute, $2628 \mathrm{CD}$ Delft, The Netherlands. Contact e-mail: eivani@m2i.nl J. ZHOU and J. DUSZCZYK, Associate Professors, are with the Department of Materials Science and Engineering, Delft University of Technology, 2628 CD Delft, The Netherlands.

Manuscript submitted May 1, 2008.

Article published online January 21, 2009 series aluminum alloys is rather scarce in the literature. Although some researchers have studied the microstructural changes and the evolution of the eutectic and low melting point phases during homogenization in the case of 7XXX series aluminum alloys, there is still a lack of information in the case of AA7020 aluminum alloy. Moreover, there is no comprehensive quantitative study on the dependence of the particles on homogenization treatment parameters. Most of the investigations have been focused on the qualitative studies of the microstructural evolution and phase transformations during homogenization. For example, Lim et al. ${ }^{[10]}$ investigated the effects of constitutional changes and preheat conditions on the evolution of constitutive particles, the M, T, and S phases, and dispersoids in AA7175 and AA7050 alloys. Senkov et al. ${ }^{[21]}$ studied the effect of homogenization treatment on the microstructural evolution of four newly developed 7XXX series aluminum alloys to obtain optimized conditions. Jackson and Sheppard ${ }^{[22]}$ studied the effect of homogenization treatment on the microstructural changes of AA7075, 7150, and 7049. They focused on the evolution of the microstructure, low melting point phases, and the $\mathrm{M}, \mathrm{T}, \mathrm{S}, \mathrm{Al}_{3} \mathrm{Mg}_{2}$ (b), $\beta$, $\mathrm{Al}_{18} \mathrm{Cr}_{2} \mathrm{Mg}(\mathrm{E})$, and $\mathrm{CrAl}_{7}$ phases. Fan et al. ${ }^{[23]}$ studied the evolution of microstructure in an $\mathrm{Al}-\mathrm{Zn}-\mathrm{Mg}-\mathrm{Cu}$ alloy during homogenization. Ciach et al. ${ }^{[24]}$ conducted theoretical and experimental studies on the dendritic structure and its dissolution in aluminum-zinc alloys. However, the research on the commercially important AA7020 alloy is scarce. ${ }^{[3]}$ No quantitative investigation on the evolution of GB phases in AA7020 during homogenization has been carried out.

The objectives of this research were to determine the effect of homogenization treatment on the evolution of the GB phases and to establish the correlations of the 
process parameters such as time and temperature with the fraction of these phases in the structure and the dissolution mechanism of the GB phases during homogenization. Thorough investigations were performed on the effect of homogenization treatment on the evolution of the GB phases using optical microscopy (OM), X-ray diffraction (XRD) analysis, and field emission gunscanning electron microscope (FEG-SEM), and the results were quantitatively analyzed. The dependence of the fraction of the GB phases in the structure on homogenization parameters was also investigated using various quantitative methods.

\section{EXPERIMENTAL PROCEDURE}

Cubic samples $0.02 \mathrm{~m}$ in size were cut from the center of a direct-chill (DC) cast AA7020 ingot. The chemical composition of the alloy is shown in Table I. Isothermal homogenization treatments were performed in a salt bath at temperatures of $390^{\circ} \mathrm{C}, 430{ }^{\circ} \mathrm{C}, 470{ }^{\circ} \mathrm{C}, 510^{\circ} \mathrm{C}$, and $550{ }^{\circ} \mathrm{C}$ for $2,4,8,16,24$, and 48 hours. Following the heat treatment, the samples were quenched in water.

Optical microscopy was performed using an Olympus BX60M light microscope on the samples etched using Barker's etchant. The OM images were analyzed using the soft imaging software (SIS) image processor. Three samples in each homogenization condition were prepared and the analysis was performed on two images with approximately 62 mega pixel image quality, and the average value is reported. The differences between the measured data from different samples and different images are represented by error bars.

The samples were also examined using a JEOL* 6500

*JEOL is a trademark of Japan Electron Optics Ltd., Tokyo.

FEG-SEM. The optimum operating voltage for resolving the particles was found to be $10 \mathrm{kV}$, which ensured a sufficient penetration depth of electrons. The SEM images of the GB particles after different homogenization treatments were quantitatively analyzed to investigate the dissolution of the GB particles during homogenization. $20 \mathrm{~GB}$ particles were analyzed in each case, and the width was measured and the average value calculated. During homogenization at high temperatures, i.e., $510^{\circ} \mathrm{C}$ and $550{ }^{\circ} \mathrm{C}$, some of the $\mathrm{GB}$ particles were completely dissolved in the structure. The dissolved GB particles were also considered in the calculation with a null width. The average initial number density of the GB particles in 20 micrographs of the structure was counted to be $2 \cdot 10^{9} / \mu \mathrm{m}^{-2}$. The average number density of the GB particles after homogenization was also counted employing the same method; if it was less than the average initial number density, which indicated the dissolution of some of the GB phases, a zero width was put.

Energy-dispersive X-ray analysis (EDX) was performed with an analyzer attached to the FEG-SEM to determine the chemical composition of the particles. In the case of small particles $(<200 \mathrm{~nm})$, the error in the measured composition using EDX was large due to the spread of electrons into the matrix lying underneath the particle. To decrease the error in the EDX measurements, the analysis was performed on TEM samples with an average thickness of $100 \mathrm{~nm}$. Disks with a diameter of $3 \mathrm{~mm}$ were punched from the samples and ground down to less than $60 \mu \mathrm{m}$, followed by electropolishing in a double-jet polishing unit at $20 \mathrm{~V}$ in a solution of 30 pet nitric acid and 70 pet methanol cooled to $-25^{\circ} \mathrm{C}$. To determine the concentrations of the elements in the structure, the EDX analysis was performed at different positions of the TEM sample and an average of five measurements is reported.

A Bruker-AXS D5005 diffractometer with $\mathrm{Cu} K_{\alpha 1}$ wavelength was used to identify the phases present in the as-cast and as-homogenized conditions. Quantitative XRD (QXRD) analysis was performed using the direct comparison method ${ }^{[25]}$ to estimate the weight percent of the phases in the structure. The application of this method requires the weight percent of the phase of interest (herein the GB phase) in the as-cast structure, as the baseline. To calculate the weight percent of the GB phases in the as-cast structure, the surface fraction of the GB phases was calculated using FEG-SEM together with EDX analysis. The analysis was performed on 20 images at a magnification of 1000 times, and all the particles present in each image were analyzed. Assuming a uniform distribution of the GB phases in the structure, the surface fraction can be approximated to be equal to the volume fraction. The volume fraction of the GB phases was converted to weight percent using the density of the $\mathrm{GB}$ phases $\left(3709 \mathrm{~kg} / \mathrm{m}^{3[26,27]}\right)$ and the density of AA7020 aluminum alloy $\left(2780 \mathrm{~kg} / \mathrm{m}^{3[28]}\right)$. The only assumption made was the density of the other particles (a mixture of various phases) other than the GB phases being equal to the density of AA7020 aluminum alloy.

\section{RESULTS}

\section{A. As-Cast Microstructure}

Low and higher-magnification secondary electron FEG-SEM images of the as-cast microstructure of the AA7020 aluminum alloy are shown in Figure 1. The constitutive particles elongated along the grain boundaries can be clearly seen. The average width of these GB phases is $640 \mathrm{~nm}$. The perturbations on the surfaces of the GB phases are illustrated with arrows in Figure 1(b).

Table I. Chemical Composition of the Alloy Used in This Study

\begin{tabular}{lccccccccccc}
\hline Element & $\mathrm{Si}$ & $\mathrm{Fe}$ & $\mathrm{Cu}$ & $\mathrm{Mn}$ & $\mathrm{Mg}$ & $\mathrm{Zn}$ & $\mathrm{Ti}$ & $\mathrm{Cr}$ & $\mathrm{Zr}$ & $\mathrm{Al}$ \\
\hline Wt pet & 0.30 & 0.30 & 0.19 & 0.35 & 1.20 & 4.37 & 0.002 & 0.10 & 0.13 & bal \\
\hline
\end{tabular}



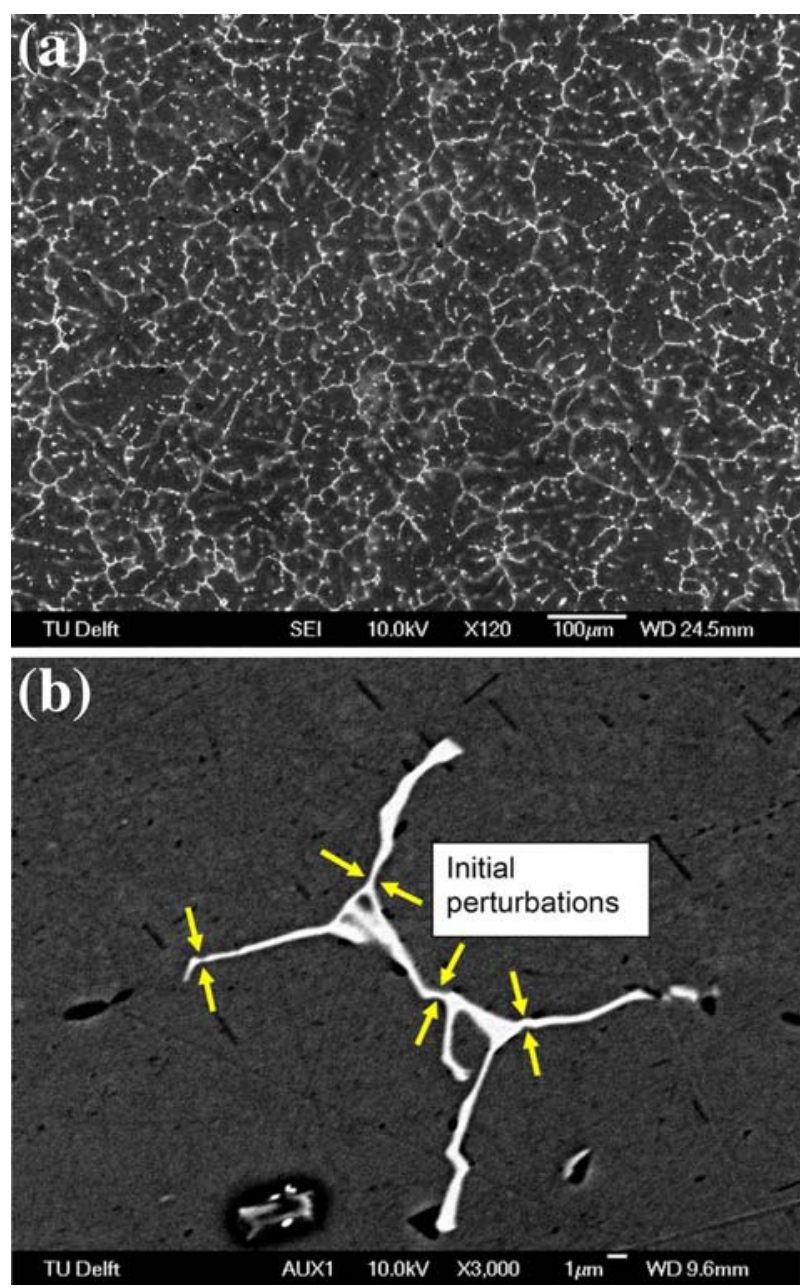

Fig. 1-(a) Low- and (b) higher-magnification SEM micrographs showing the GB phases in the as-cast microstructure.
In order to determine the composition of these GB phases, EDX on more than $20 \mathrm{~GB}$ phases having the same morphology was performed. The results showed that the majority of the GB phases had the same composition, as given in Table II. The results of the image analysis indicated that the volume fraction of the GB phases was close to 7 pct. Therefore, it was possible to determine the identity of these phases using XRD analysis. ${ }^{[25]}$ The results, shown in Figure 2, illustrate that only one secondary phase could be detected, which was $\mathrm{Al}_{17}\left(\mathrm{Fe}_{3.2}, \mathrm{Mn}_{0.8}\right) \mathrm{Si}_{2}$ (PDF No. 01-071-4015 ${ }^{[26]}$ ). Comparison of the XRD results with the EDX analysis, as given in Table II, shows good agreement.

\section{B. Effect of Homogenization}

\section{As-homogenized microstructure}

Figure 3 shows the optical microstructures of the material after 2 hours of homogenization at different temperatures. Homogenization at $390{ }^{\circ} \mathrm{C}$ and $430{ }^{\circ} \mathrm{C}$ led to an increase in the volume fraction of particles. At $470{ }^{\circ} \mathrm{C}$, the volume fraction appeared to be unchanged, while at $510{ }^{\circ} \mathrm{C}$ and $550{ }^{\circ} \mathrm{C}$, it decreased. Figure 4 shows low and higher-magnification secondary electron FEGSEM images of the dominant phases formed during homogenization at $390{ }^{\circ} \mathrm{C}$. The grain boundaries are still delineated by the GB phases, while the initial continuity of the GB phases shown in Figure 1(a) is deteriorated by spheroidization. Moreover, large needleshaped and round precipitates appear in the structure. Examples of these precipitates together with large Al-Fe-Si particles are illustrated in Figure 4(b). These phases, as pointed out in Figure 4(a), are dispersed inside the grains. The EDX analysis on more than 20 particles with the same morphology determined the chemical compositions of these precipitates, and the results are shown in Table III.

Table II. Measured Mean Compositions (Weight Percent) of the GB Constitutive Particles in the As-Cast Material Together with the Calculated Chemical Compositions of the Suggested Phase Identity Based on the XRD Analysis

\begin{tabular}{|c|c|c|c|c|c|c|}
\hline Element & $\mathrm{Al}$ & $\mathrm{Fe}$ & $\mathrm{Mn}$ & $\mathrm{Si}$ & $\mathrm{Zn}$ & $\mathrm{Cu}$ \\
\hline $\mathrm{GB}(\mathrm{EDX})$ & $72 \pm 3$ & $16 \pm 2$ & $3 \pm 1$ & $4 \pm 1$ & $3 \pm 1$ & $2.0 \pm 0.4$ \\
\hline $\mathrm{Al}_{17}\left(\mathrm{Fe}_{3.2}, \mathrm{Mn}_{0.8}\right) \mathrm{Si}_{2}(\mathrm{XRD})$ & 62.19 & 24.23 & 5.96 & 7.62 & - & - \\
\hline
\end{tabular}

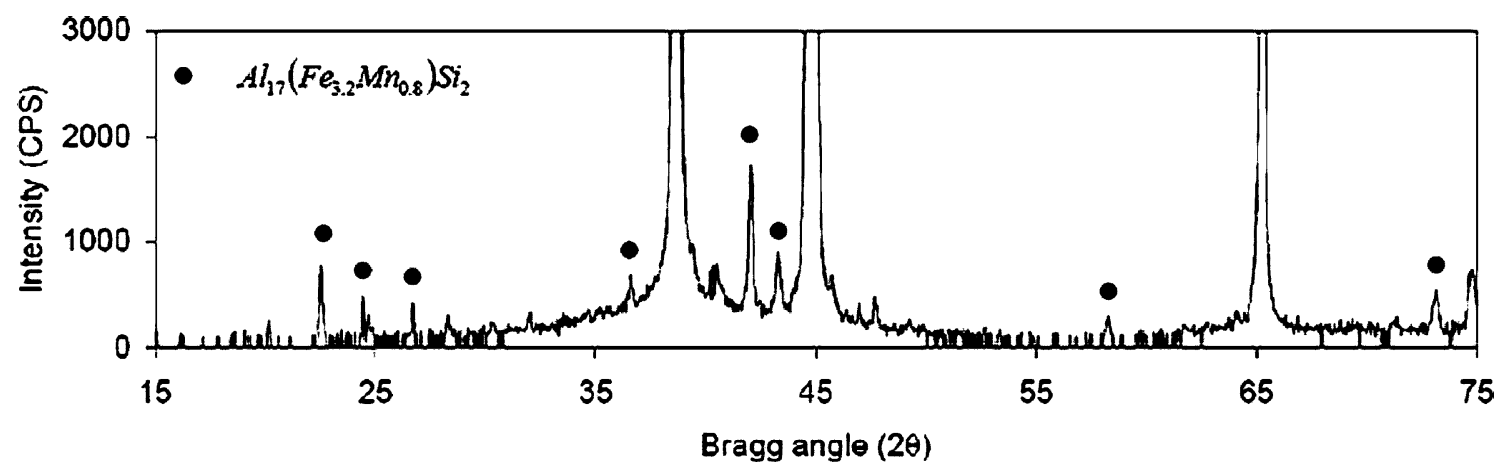

Fig. 2-XRD pattern of the as-cast material showing the presence of the GB phases. 

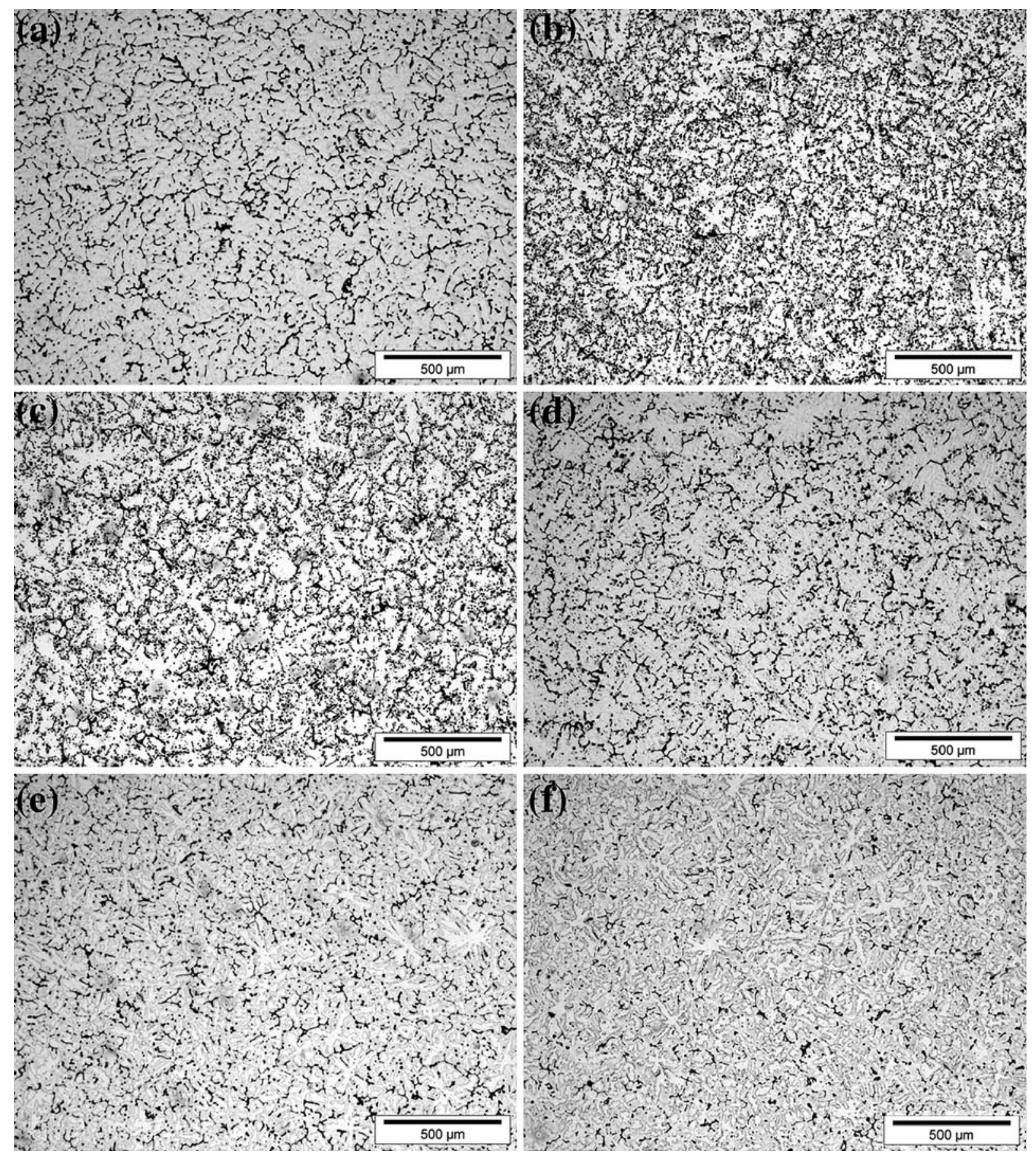

Fig. 3-Effect of the temperature of homogenization for $2 \mathrm{~h}$ on the evolution of particles: $(a)$ initial structure, $(b) 390{ }^{\circ} \mathrm{C},(c) 430{ }^{\circ} \mathrm{C},(d) 470{ }^{\circ} \mathrm{C}$, (e) $510{ }^{\circ} \mathrm{C}$, and $(f) 550{ }^{\circ} \mathrm{C}$

It was possible to identify these compounds formed during homogenization at low temperatures using XRD analysis. The results illustrated in Figure 5(a) show that, in addition to the previously present GB phases (Figure 2), new phases are present in the homogenized microstructure, i.e., $\mathrm{MgZn}_{2}(\eta)$ and $\mathrm{Mg}_{2} \mathrm{Si}(\beta)$ particles. However, the XRD pattern of the sample homogenized at $550{ }^{\circ} \mathrm{C}$, presented in Figure 5(b), shows that no new phases have been formed during homogenization at these high tempera- tures, which is consistent with the results from the $\mathrm{OM}$ analysis shown in Figure 3.

It was also found that, even after homogenization at a high temperature, i.e., $550{ }^{\circ} \mathrm{C}$, some of the particles were not dissolved in the structure. These retained particles are mostly the GB phases and other particles, which together with their EDX spectrum are typically shown in Figures 6(a) and (b). The EDX suggested that the particles shown in Figures 6(a) and (b) are $\mathrm{Al}_{13} \mathrm{Fe}_{4}$ and $\mathrm{Al}_{8} \mathrm{Fe}_{2} \mathrm{Si}$, respectively. 

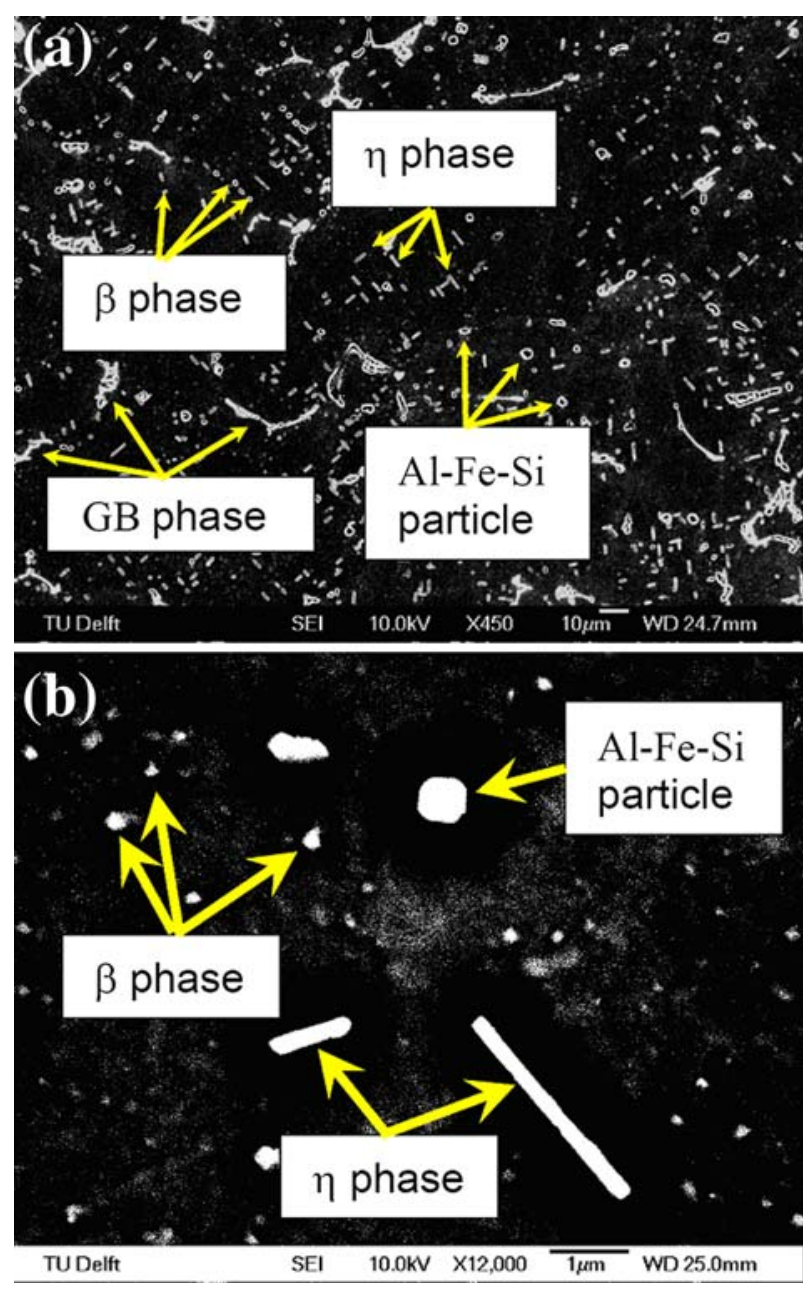

Fig. 4 - (a) Low-magnification FEG-SEM image of the material homogenized at $390{ }^{\circ} \mathrm{C}$, and $(b)$ the needle-shaped and round $\mathrm{MgZn}_{2}$ $(\eta)$ and $\mathrm{Mg}_{2} \mathrm{Si}(\beta)$ particles together with large Al-Fe-Si particles.

Table III. Measured Mean Compositions (Weight Percent) of the Needle-Shaped and Round Precipitates in the As-Homogenized Microstructure Together with the Stoichiometric Chemical Compositions Based on the XRD Results

\begin{tabular}{lccccc}
\hline Element (Wt Pct) & $\mathrm{Al}$ & $\mathrm{Mg}$ & $\mathrm{Zn}$ & $\mathrm{Si}$ & $\mathrm{Fe}$ \\
\hline$\eta$ Phase (EDX) & $63 \pm 4$ & $4 \pm 2$ & $28 \pm 1$ & $3 \pm 1$ & $2 \pm 1$ \\
$\eta$ Phase (XRD) & - & 15.7 & 84.3 & - & - \\
$\beta$ Phase (EDX) & $56 \pm 4$ & $22 \pm 3$ & $5 \pm 2$ & $15 \pm 3$ & $2 \pm 2$ \\
$\beta$ Phase (XRD) & - & 63.38 & - & 36.62 & - \\
\hline
\end{tabular}

\section{Quantitative analysis using $O M$}

Figure 7 shows the effect of homogenization time on the volume fraction of all the particles present in the structure. The calculation was based on the changes in the volume fraction of the particles in the structure typically presented in Figure 3 . It is clear that, at $390{ }^{\circ} \mathrm{C}$ and $430{ }^{\circ} \mathrm{C}$, there is an increase in the fraction of particles, while at $510{ }^{\circ} \mathrm{C}$ and $550{ }^{\circ} \mathrm{C}$, the fraction of the particles decreases, indicating dissolution.

\section{Quantitative XRD analysis}

Figure 8 compares the strongest XRD peak and another one related to the GB phase in the AA7020 samples homogenized for 8 hours at different temperatures. This figure was obtained by focusing on the 41 to 44 deg Bragg's angle (2 $\theta)$ range in the XRD patterns, i.e., Figures 2 and 5. Compared with the as-cast structure, it is obvious that the intensity of the peaks related to the $\mathrm{GB}$ phases in the samples homogenized at $390{ }^{\circ} \mathrm{C}$ is almost unchanged, while at $430{ }^{\circ} \mathrm{C}$ and $470{ }^{\circ} \mathrm{C}$, it is decreased slightly, which is directly related to the fraction of the GB phases, indicating that the fraction of the GB phases is almost unchanged. Homogenization treatment at higher temperatures, namely, $510{ }^{\circ} \mathrm{C}$ and $550{ }^{\circ} \mathrm{C}$, resulted in a decrease in the intensity of the peaks related to the GB phases in the $\mathrm{XRD}$ pattern in comparison with the as-cast structure.

In order to quantify the results, the fraction of the GB phases in the structure after homogenization was calculated according to the results of the XRD analysis using the direct comparison method. ${ }^{[25]}$ The initial fraction of the GB phases with respect to all of the secondary phases in the as-cast structure, which is necessary as the baseline for the direct comparison method, was calculated to be equal to $74 \pm 3 \mathrm{wt}$ pct by the methodology presented in the experimental procedure. Figure 9 illustrates the weight percent of the GB phases as a function of homogenization time at different temperatures. It can be seen that the fraction of the GB phases after homogenization at $390{ }^{\circ} \mathrm{C}$ remains unchanged, and at $430{ }^{\circ} \mathrm{C}$, it is decreased slightly, which is not in agreement with the results of the quantitative optical microscopy (QOM) shown in Figure 7. Therefore, in Figure 7, as shown earlier, the increase in the fraction of phases during homogenization is due to the formation of new precipitates $(\eta$ and $\beta$ ) and not the increase in the GB phases. However, at higher temperatures, the fraction of GB phases decreases, which is in line with the behavior shown in the QOM results.

\section{Ouantitative analysis using FEG-SEM}

The measured average widths of the GB phases as a function of homogenization time are shown in Figure 10 . It can be seen that, at $390^{\circ} \mathrm{C}$ and $430{ }^{\circ} \mathrm{C}$, the average width of the GB phases is almost unchanged from the initial value. The minor variations in the width of the GB phases at these temperatures are within the margin of error. However, at higher temperatures, dissolution occurs, evidenced by the decreases in the width of the GB phases. It can also be seen in Figure 10 that the most rapid dissolution occurs at the first few hours of homogenization regardless of the treatment temperature. Moreover, the dissolution rate is much higher at $550{ }^{\circ} \mathrm{C}$.

\section{Evolution of $G B$ phases during homogenization}

The evolution of a typical GB phase during homogenization at $390{ }^{\circ} \mathrm{C}$ and $550{ }^{\circ} \mathrm{C}$ is shown in Figures 11 and 12 , respectively. It is clear that the dominant process at lower temperatures is the spheroidization of the GB phases, while at higher temperatures, the decrease in the width of the GB phases is the main evolution process. 


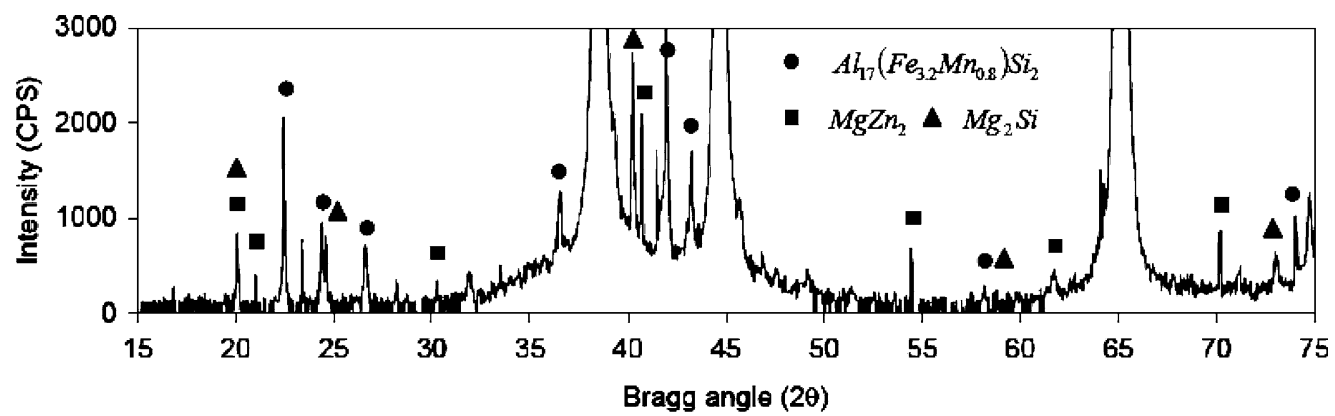

(a)

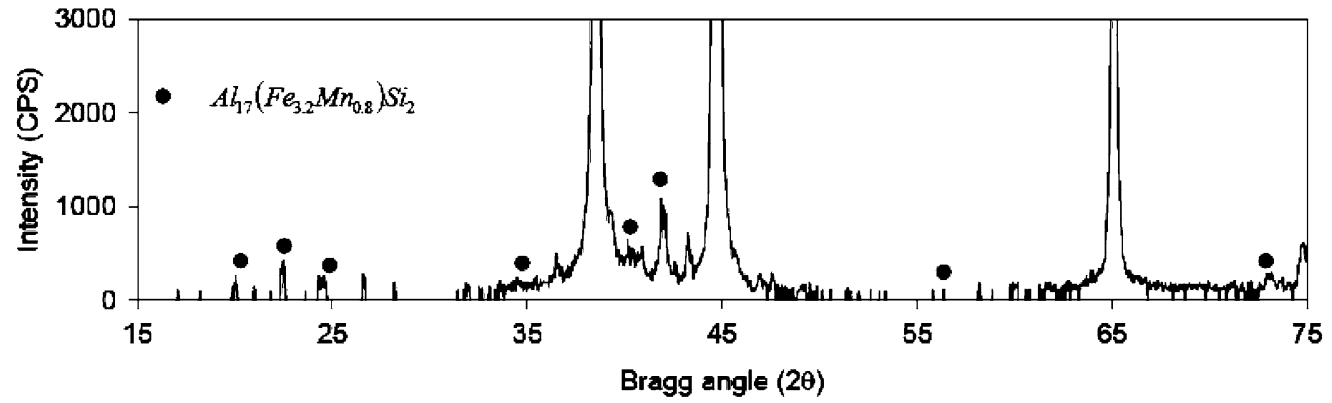

(b)

Fig. 5-XRD patterns of the material homogenized at (a) $430{ }^{\circ} \mathrm{C}$ and $(b) 550{ }^{\circ} \mathrm{C}$ showing the presence of the $\mathrm{GB}_{\text {phases, }} \mathrm{MgZn}_{2}(\eta)$ and $\mathrm{Mg} \mathrm{S}_{2} \mathrm{Si}$ ( $\beta)$ particles.
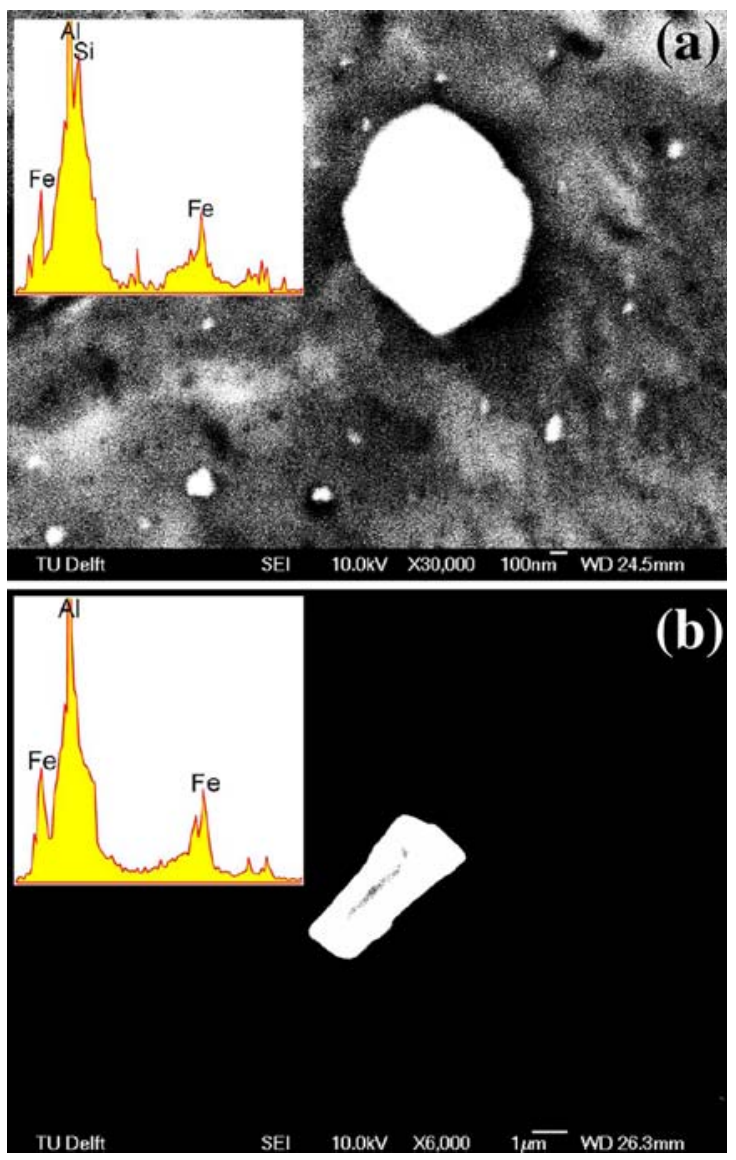

Fig. 6-Particles remaining in the microstructure after homogenization at $550{ }^{\circ} \mathrm{C}$ for $48 \mathrm{~h}$ : (a) $\mathrm{Al}_{8} \mathrm{Fe}_{2} \mathrm{Si}$ and $(b) \mathrm{Al}_{13} \mathrm{Fe}_{4}$ particle.

\section{DISCUSSION}

\section{A. Effect of Homogenization Treatment on the Microstructure}

\section{As-homogenized microstructure}

The investigations carried out using the FEG-SEM of the samples homogenized at $390{ }^{\circ} \mathrm{C}$ and $430{ }^{\circ} \mathrm{C}$ indicated the presence of needle-shaped and round precipitates, as shown in Figure 4. The morphology of these particles and their chemical compositions indicated these particles to be $\mathrm{MgZn}_{2}$ and $\mathrm{Mg}_{2} \mathrm{Si}$ precipitates, which is in agreement with References 29 through 31. The formation of these precipitates may be attributed to the supersaturation of the structure with alloying elements due to microsegregation during solidification with high cooling rates applied during DC casting. When the as-cast alloy is exposed to a homogenization treatment at a low temperature $\left(<470{ }^{\circ} \mathrm{C}\right)$, there is a tendency for the alloying elements to precipitate out. As the temperature increases $\left(>470{ }^{\circ} \mathrm{C}\right)$, the solubility of these elements in the $\alpha$-Al matrix increase ${ }^{[32,33]}$ and the formation of new phases is not expected. Thus, it can be concluded that the formation of new phases or the dissolution of old ones depends primarily on the homogenization temperature.

\section{Quantitative analysis using $O M$}

The most noticeable outcome of Figure 7 is the increase in the fraction of all the particles during homogenization at low temperatures, which acts in contrary to the aim of the homogenization process. ${ }^{[3]}$ This increase in the fraction of particles during the first 2 hours of homogenization at $390{ }^{\circ} \mathrm{C}$ and $430{ }^{\circ} \mathrm{C}$, as 


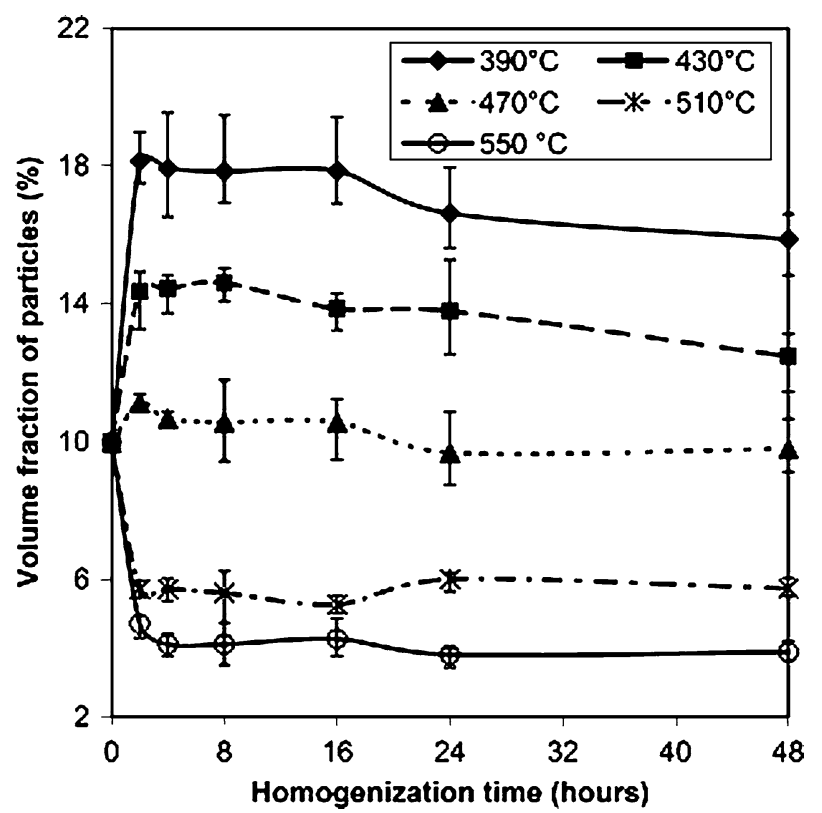

Fig. 7-Effect of homogenization time on the volume fraction of particles.

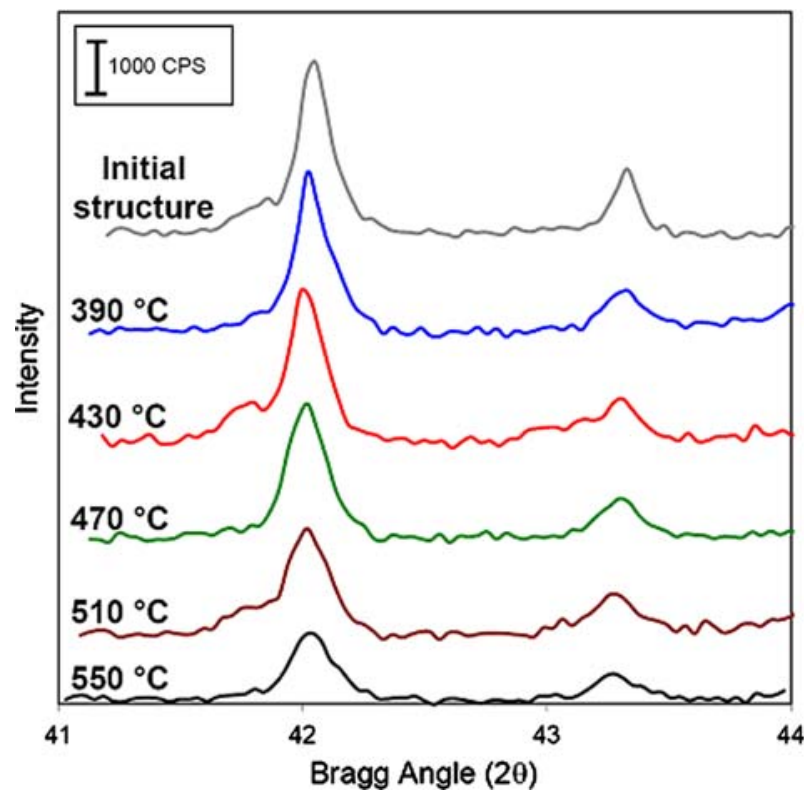

Fig. 8-Strongest (left) and another (right) XRD peak related to the GB phases in samples homogenized for 8 hours at different temperatures.

shown in Figure 7, is due to the formation of a significant number of new particles, namely, $\mathrm{MgZn}_{2}$ $(\eta)$ and $\mathrm{Mg}_{2} \mathrm{Si}(\beta)$. As stated previously, this finding indicates that part of the elements precipitate out by forming precipitates during the first 2 hours of homogenization.

To account for the dissolution of the GB phases, a study on the solubility limits of the elements composing the main GB phase, namely, $\mathrm{Fe}, \mathrm{Mn}$, and $\mathrm{Si}$, is essential. The data on the solubility limits of the elements in

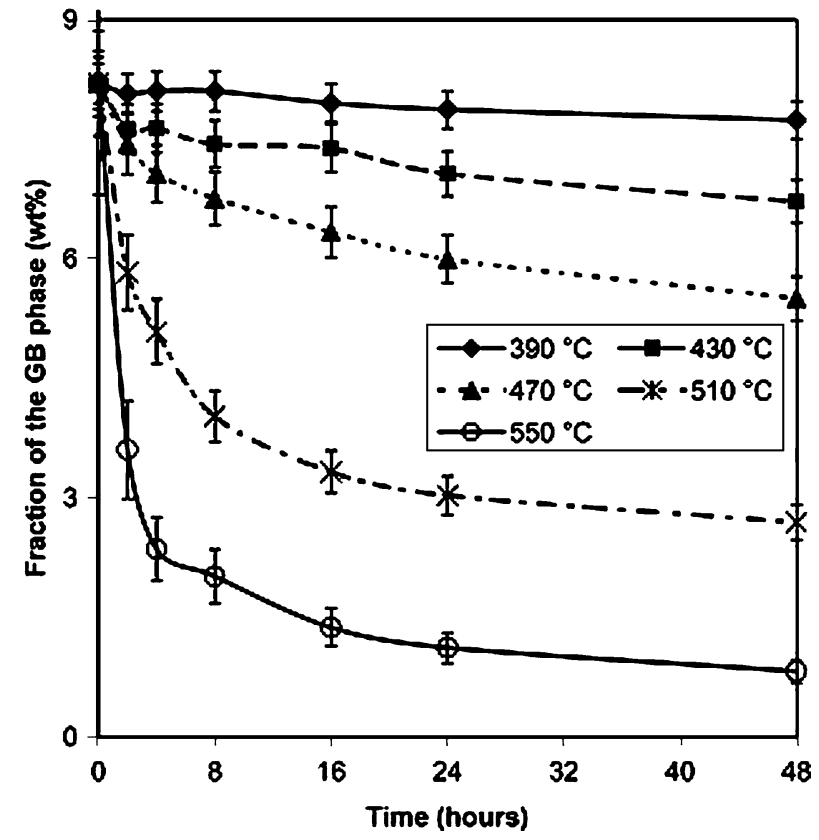

Fig. 9-Fraction of the GB phases (wt pct) in the structure after homogenization at various temperatures, based on the QXRD analysis.

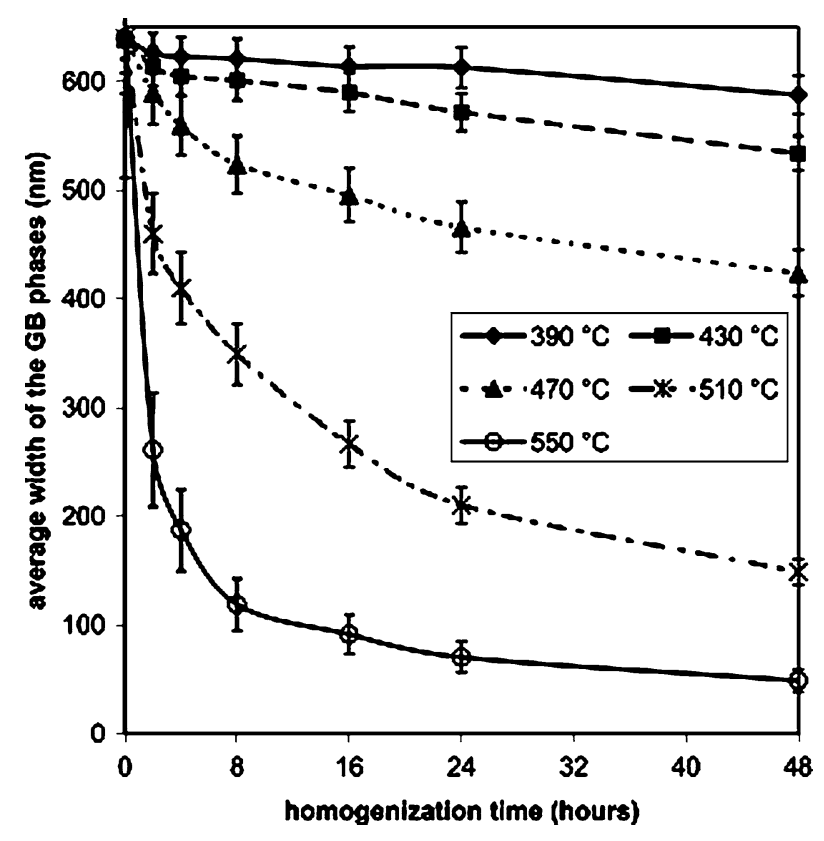

Fig. 10-Average GB widths as a function of homogenization time, based on the QSEM analysis.

$\mathrm{Al}-\mathrm{Mn}-\mathrm{Fe}-\mathrm{Si}$ are scarce in the literature ${ }^{[32]}$ In this case, the solubility of the elements in $\mathrm{Al}$ in the four-component $\mathrm{Al}-\mathrm{Mn}-\mathrm{Fe}-\mathrm{Si}$ regions adjacent to the ternary systems may be estimated, based on three-component regions of the $\mathrm{Al}-\mathrm{Fe}-\mathrm{Mn}, \mathrm{Al}-\mathrm{Fe}-\mathrm{Si}$, and $\mathrm{Al}-\mathrm{Mn}-\mathrm{Si}$ ternary systems. ${ }^{[32]}$ Table IV shows the solid solubility limits of iron, manganese, and silicon in the fourcomponent $\mathrm{Al}-\mathrm{Fe}-\mathrm{Mn}-\mathrm{Si}$ system at different temperatures. ${ }^{[32]}$ It is clear that, at low temperatures, i.e., lower 

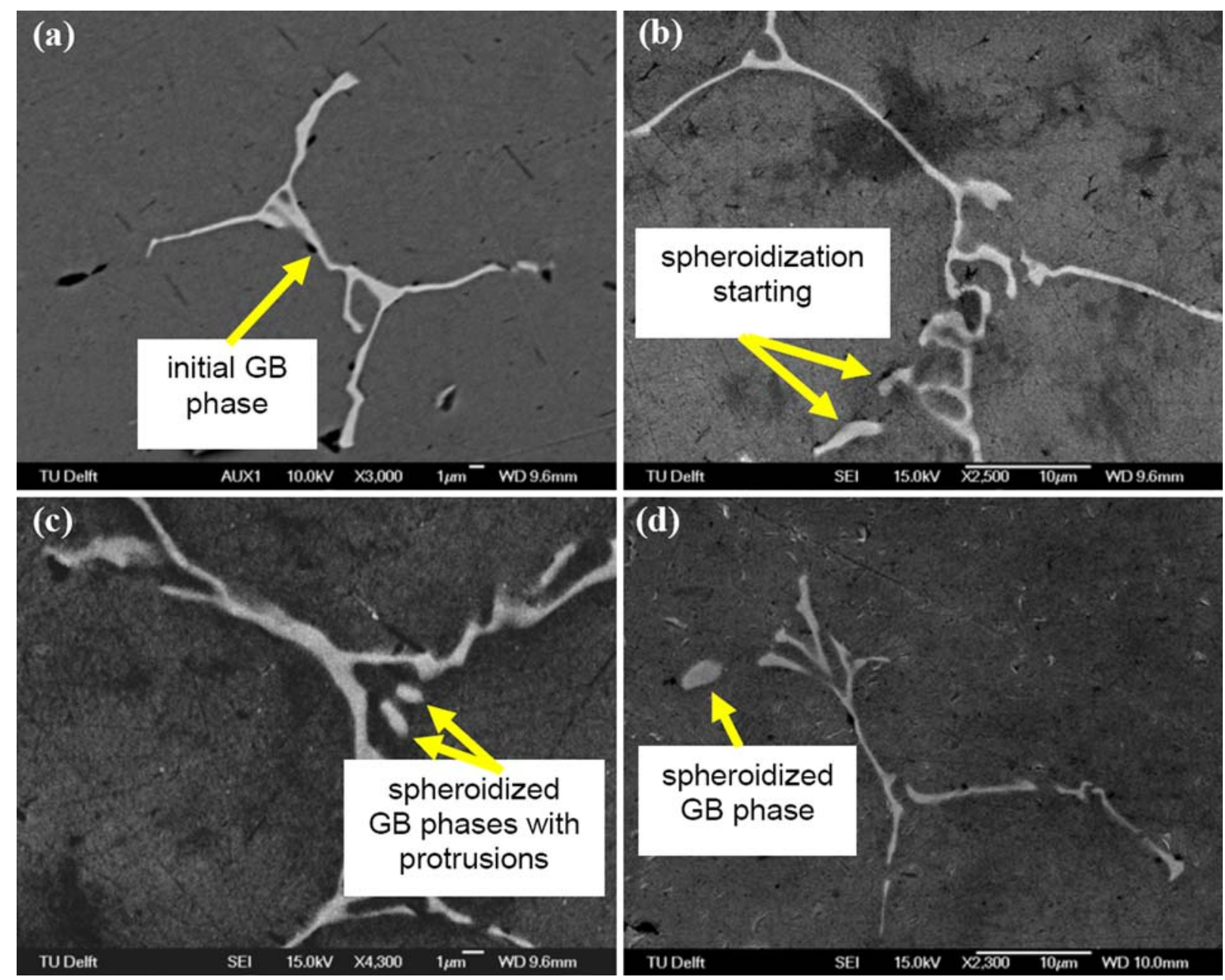

Fig. 11-Typical shapes of the GB phases after homogenization at $390^{\circ} \mathrm{C}:(a)$ initial, (b) $2 \mathrm{~h},(c) 8 \mathrm{~h}$, and (d) $24 \mathrm{~h}$.

than $470{ }^{\circ} \mathrm{C}$, the solubility limits of the elements forming the GB components are small in the $\alpha$-Al matrix. Therefore, considerable dissolution of the GB phases is not expected at these temperatures. This is in agreement with the results of the quantitative image analyses of the $\mathrm{OM}$ images, presented in Figure 7. At higher temperatures, however, the solubility limits increase, as shown in Table IV, which indicates that most of the alloying elements along the GB phases are dissolved in the $\alpha$-Al matrix. It is also clear that, even at such high temperatures $\left(\right.$ e.g., $\left.550{ }^{\circ} \mathrm{C}\right)$, the solubility limits of the elements in the Al matrix are less than the weight percentages of those elements in the composition of the alloy. Therefore, complete dissolution of all the GB phases is not expected even after holding for a long time. This explains the observation in Figure 3(f) that there are still some GB phases remaining in the structure after homogenization at $550^{\circ} \mathrm{C}$. The EDX analyses confirmed the existence of these phases even after homogenization at $550{ }^{\circ} \mathrm{C}$ for 48 hours.

\section{3. $Q X R D$ and quantitative FEG-SEM analysis}

The benefit of using QXRD analysis is that the results obtained are primarily related to the GB phases while the QOM analysis includes the GB phases, the later formed $\eta$ and $\beta$ precipitates, and other particles present. In addition, QOM gives useful quantitative information on the amounts of the phases formed during homogenization. In Figure 7, as discussed earlier, the increase in the fraction of phases during homogenization at low temperatures is due to the formation of new precipitates $(\eta$ and $\beta$ ) rather than the increase in the GB phases. On the other hand, the volume fraction of the GB phases is almost unchanged, as shown in Figure 9. Therefore, the difference between the results of QOM and QXRD in the fraction of the particles during homogenization at $390{ }^{\circ} \mathrm{C}$ and $430{ }^{\circ} \mathrm{C}$ is due to the difference mentioned previously. Consequently, the combination of the results of both of the quantitative instruments is essential to the investigation of the evolution of the microstructure during homogenization treatment.

The slight decrease in the fraction of the GB phases during homogenization at low temperatures means that the kinetics of the dissolution of these phases at these temperatures $\left(<430{ }^{\circ} \mathrm{C}\right)$ is relatively slow. Because the fraction of the GB phases decreases significantly at a homogenization temperature of $510^{\circ} \mathrm{C}$ and higher, it is concluded that, in order to dissolve the GB phases, 

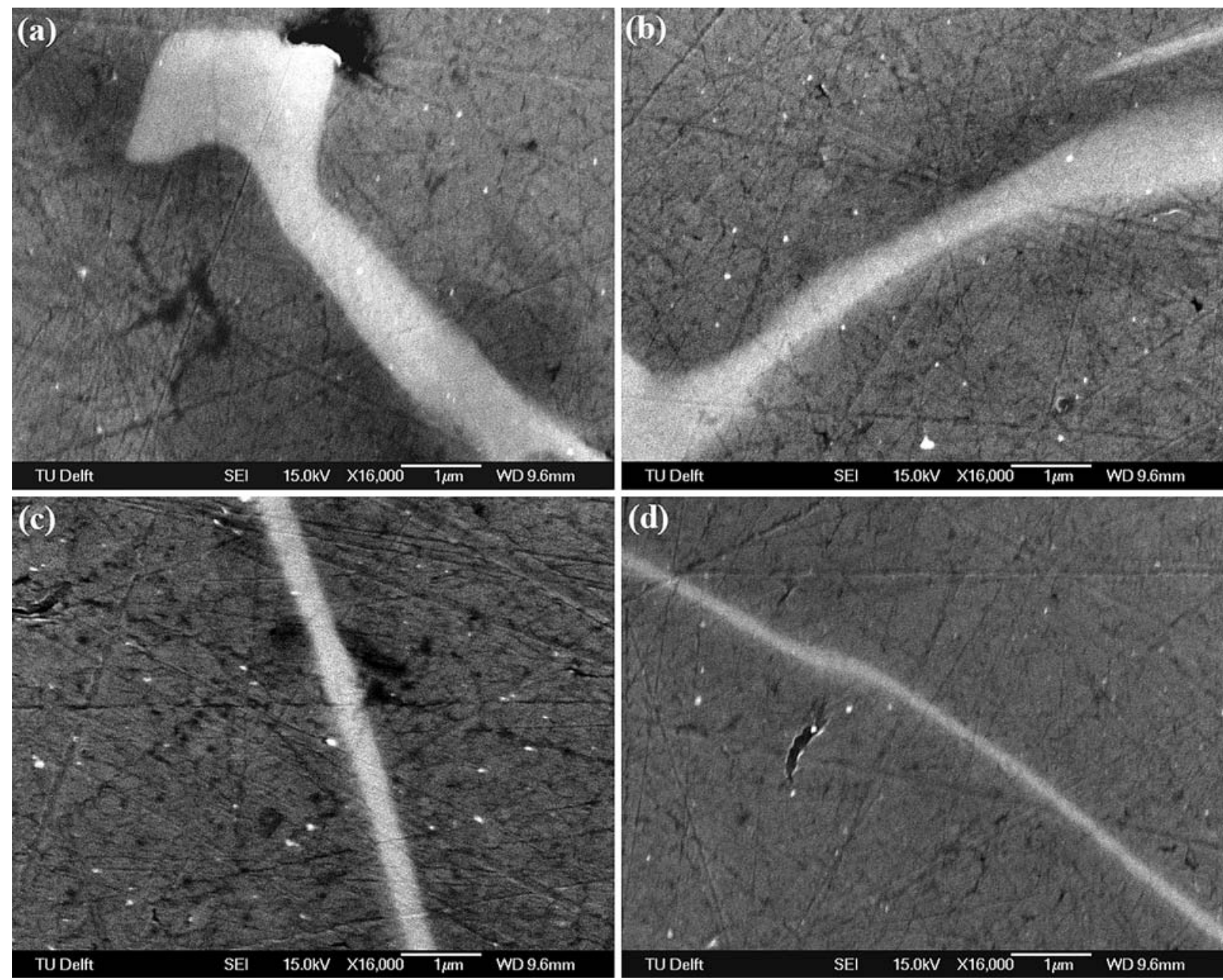

Fig. 12-Typical decrease in the width of the GB phases after homogenization at $550{ }^{\circ} \mathrm{C}:(a)$ initial, (b) $2 \mathrm{~h},(c) 8 \mathrm{~h}$, and $(d) 24 \mathrm{~h}$.

Table IV. Solid Solubility Limits of Iron, Manganese, and Silicon in the Four-Component Al-Fe-Mn-Si System at Different Temperatures ${ }^{[32]}$

\begin{tabular}{lccc}
\hline & \multicolumn{3}{c}{ Solubility Limit (Wt Pct) } \\
\cline { 2 - 4 } $\mathrm{T}\left({ }^{\circ} \mathrm{C}\right)$ & $\mathrm{Fe}$ & $\mathrm{Mn}$ & $\mathrm{Si}$ \\
\hline 390 & 0.002 & 0.026 & 0.03 \\
430 & 0.004 & 0.05 & 0.06 \\
470 & 0.009 & 0.15 & 0.08 \\
510 & 0.016 & 0.25 & 0.11 \\
550 & 0.044 & 0.44 & 0.2 \\
\hline
\end{tabular}

applying a homogenization treatment at $510^{\circ} \mathrm{C}$ or higher is necessary.

In the case of quantitative FEG-SEM analysis (QSEM) analysis, an unchanged width means that no dissolution has occurred and any decrease in the widths of the GB phases is the result of dissolution. The general trend of the change in the width of the GB phases during homogenization using QSEM analysis (Figure 10) agrees with that of the fractions of the phases from the QXRD analysis.

\section{B. Mechanisms of the Evolution of the GB Phases during Homogenization}

Unlike the evolution of other phases in different aluminum alloys, ${ }^{[2,3,22,23]}$ the evolution of the GB phases during homogenization, depending on the process parameters and the nature of the phases, may occur in the form of spheroidization or dissolution. The spheroidization mechanism of these phases is quite interesting. However, more interestingly, the dissolution of the GB phases obeys a specific dissolution mechanism introduced as the thinning, discontinuation, and full dissolution (TDFD) mechanism hereafter, which has not been reported elsewhere for aluminum alloys.

\section{Spheroidization during homogenization} at low temperatures

The analysis of the SEM images indicates that, although the fraction of the GB phases does not decrease during homogenization at $390{ }^{\circ} \mathrm{C}$, the morphological changes toward spheroidization take place, as can be seen in Figure 11. The analysis of 20 pictures from the as-cast structure and the one homogenized at $390{ }^{\circ} \mathrm{C}$ for 48 hours indicates that, after homogenization, the 
fraction of spheroidized particles increases 2 times compared with the as-cast structure. Because the GB phases are delineated along the grain boundaries as plates, spheroidization results in a decrease in their specific surface area, even though no changes have occurred in their actual volume fraction. Then, a decrease in the surface fraction of the GB phases is expected even without any changes in their volume fraction. Thus, the gradual decrease in the surface fraction of the GB phases in the samples homogenized at $390{ }^{\circ} \mathrm{C}$ in Figure 7 from 4 to 48 hours is due to the spheroidization of the GB phases.

The proposed mechanism of the spheroidization of the GB phases is illustrated in Figure 13, based on the experimental observations from the FEG-SEM images (a typical one is shown in Figure 11). Figure 13(a) shows a GB phase with initial protrusions on its surface. Afterward, spheroidization occurs and the GB phase takes an ellipse shape (Figure 13(b)). The spheroidization continues until the GB phase takes a spherical shape with protrusions on its surface (Figure 13(c)), and the process ends with removal of the protrusions until the GB phase resembles a flat surface sphere (Figure 13(d)). The driving force for spheroidization is the decrease in the surface energy of the GB phases with decreasing interfacial length between the GB phases and the aluminum matrix. ${ }^{[2,34]}$

\section{TDFD during homogenization at high temperatures}

In order to understand the dissolution sequence of the GB phases at high homogenization temperatures, the evolution of a GB phase was investigated at different time intervals during homogenization at $550{ }^{\circ} \mathrm{C}$. It was found that the dissolution process started with the thinning of the GB phase without primary spheroidization. Figure 10 shows that the average width of the GB phase decreases from 640 to $130 \mathrm{~nm}$ when a homogenization treatment at $550{ }^{\circ} \mathrm{C}$ for 48 hours is employed. The thinning process continues until the GB phase becomes discontinuous in some regions (Figure 14) and, finally, the full dissolution of the GB phase occurs. The occurrence of discontinuities during spheroidization of eutectic phases has been reported elsewhere, for example, in Reference 35. However, the observation of discontinuities without primary spheroidization and their effects on the dissolution of the particles has not been reported.

The dissolution mechanism of the GB phases with its intermediate stages is schematically illustrated in Figure 15. The driving force for this behavior is the increase in the solubility limits in the matrix at high temperatures and, therefore, the presence of concentration gradients of $\mathrm{Mn}, \mathrm{Fe}$, and $\mathrm{Si}$ in the structure. Figures 15(a) through (c) schematically illustrate the overall thinning process of the GB phases. Assuming that during homogenization an overall decrease in the width of the GB phase occurs at a constant rate in different regions regardless of the widths (Figures 15(a) through (c)), the parts having smaller widths meet each other sooner than other parts, as shown with arrows in Figure 15(d). Therefore, the discontinuities (Figure 15(e)) occur as a result of the inherent perturbations (Figure 1(b)) of the surfaces of the GB phase, shown by arrows in Figure 15(a). Afterward, the dissolution

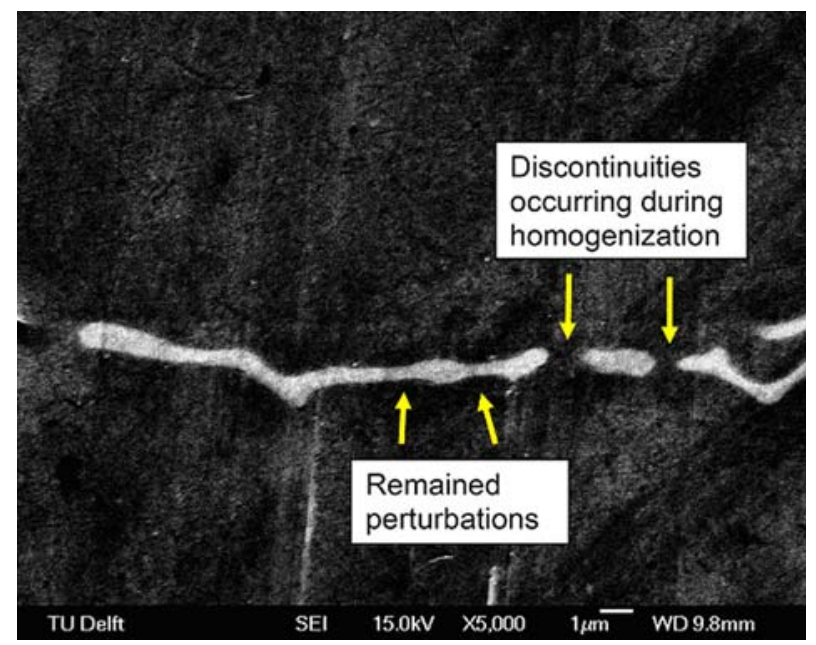

Fig. $14-\mathrm{GB}$ phases after homogenization at $550^{\circ} \mathrm{C}$ for $8 \mathrm{~h}$, showing the thinning and discontinuation.

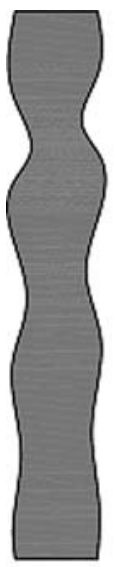

(a)

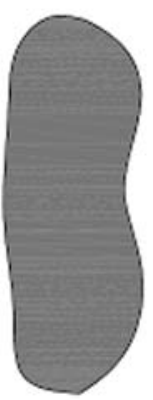

(b)

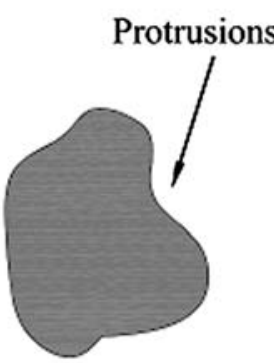

(c)

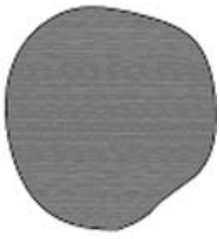

(d)

Fig. 13 - Schematic description of the spheroidization mechanism responsible for the evolution of a GB phase during homogenization at low temperatures. 


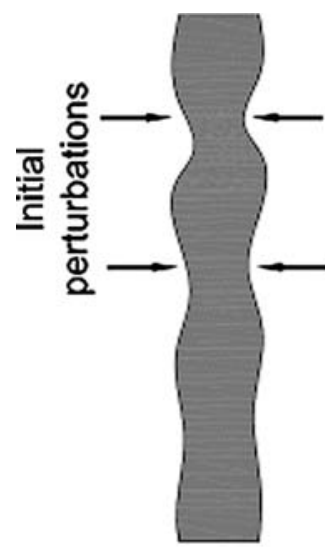

(a)

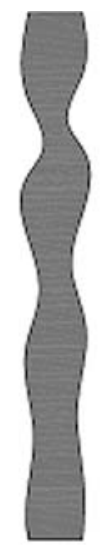

(b)

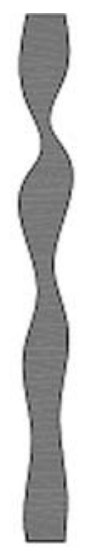

(c)

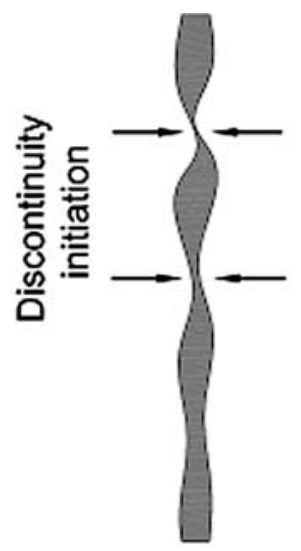

(d)

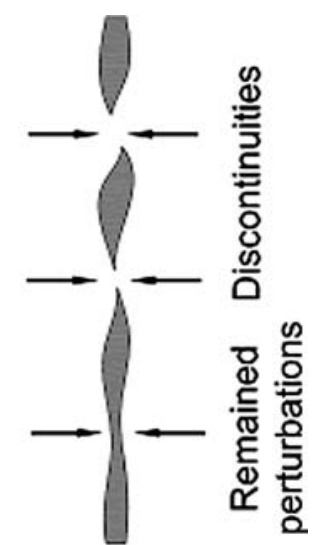

(e)

Fig. 15-Schematic description of the TDFD mechanism responsible for the evolution of a GB phase during homogenization at high temperatures.

continues with the same mechanism occurring in the small parts until the GB phase disappears. The remaining perturbations, which help the continuation of the dissolution of the GB phase with the same mechanism, are shown in Figure 15(e) with arrows.

\section{CONCLUSIONS}

The effect of the homogenization treatment of the AA7020 aluminum alloy at temperatures from $390{ }^{\circ} \mathrm{C}$ to $550{ }^{\circ} \mathrm{C}$ for 2 to 48 hours followed by water quenching on the evolution of the GB phases was investigated and the following conclusions have been drawn.

1. The particles along the grain boundaries (GB phase), which constitute more than 70 pct of the secondary phases present in the as-cast structure of the AA7020 aluminum alloy, are $\mathrm{Al}_{17}\left(\mathrm{Fe}_{3.2}, \mathrm{Mn}_{0.8}\right) \mathrm{Si}_{2}$.

2. The increase in the fraction of intermetallic particles during homogenization at low temperatures is due to the formation of $\mathrm{MgZn}_{2}(\eta)$ and $\mathrm{Mg}_{2} \mathrm{Si}(\beta)$ precipitates. At higher temperatures, however, the $\eta$ and $\beta$ precipitates do not form and instead most of the GB phases dissolve.

3. The width of the GB phases remains unchanged during homogenization at low temperatures. However, it decreases at higher temperatures. The extent of the dissolution is more dependent on homogenization temperature rather than time.

4. The evolution of the GB phases is largely dependent on temperature. The evolution mechanisms of the GB phases during homogenization consist of spheroidization during homogenization at low temperatures and TDFD at high temperatures.

\section{ACKNOWLEDGMENTS}

This research was carried out under Project No. MC 4.04203 in the framework of the Research Program of the Materials Innovation Institute M2i (www.m2i.nl), the former Netherlands Institute for Metals Research. The authors acknowledge Messrs. K. Kwakernaak, R.W.A. Hendrikx, N.M. van der Pers, and E.R. Peekstok for assistance in performing the experiments.

\section{OPEN ACCESS}

This article is distributed under the terms of the Creative Commons Attribution Noncommercial License which permits any noncommercial use, distribution, and reproduction in any medium, provided the original author(s) and source are credited.

\section{REFERENCES}

1. J.W. Martin: Precipitation Hardening, 2nd ed., ButterworthHeinemann, Oxford, United Kingdom, 1998, pp. 79-111.

2. J.D. Robson and P.B. Prangnell: Acta Mater., 2001, vol. 49, pp. 599-613

3. T. Sheppard: Extrusion of Aluminum Alloys, Kluwer Academic Publishers, Dordrecht, the Netherlands, 1999, pp. 227-52.

4. G.T. Hahn and A.R. Rosenfield: Metall. Trans. A, 1975, vol. 6A, pp. 653-68.

5. D.S. Thompson: Metall. Trans. A, 1975, vol. 6A, pp. 671-83.

6. G.G. Garrett and J.F. Knott: Metall. Trans. A, 1978, vol. 9A, pp. 1187-201.

7. F.Y. Xie, T. Kraft, Y. Zuo, C.H. Moon, and Y.A. Chang: Acta Mater., 1999, vol. 47, pp. 489-500.

8. J.S. Robinson: Mater. Sci. Technol., 2003, vol. 19, pp. 1697-701.

9. L.L. Rokhlin, T.V. Dobatkina, N.R. Bochvar, and E.V. Lysova: J. Alloys Compd., 2004, vol. 367, pp. 10-16.

10. S.T. Lim, Y.Y. Lee, and I.S. Eun: Mater. Sci. Forum, 2006, vols. 519-521, pp. 549-54.

11. C. Mondal and A.K. Mukhopadhyay: Mater. Sci. Eng. A, 2005, vol. A391, pp. 367-76.

12. R.K. Gupta, N. Nayan, and B.R. Ghosh: Can. Metall. Q., 2006, vol. 45, pp. 347-51.

13. L.L. Rokhlin, T.V. Dobatkina, N.R. Bochvar, and E.V. Lysova: J. Alloys Compd., 2004, vol. 367, pp. 10-16.

14. B. Morere, C. Maurice, R. Shahani, and J. Driver: Metall. Mater. Trans. A, 2001, vol. A32, pp. 625-32.

15. E. Clouet, A. Barbu, L. Lae, and G. Martin: Acta Mater., 2005, vol. 53 , pp. 2313-25.

16. Z. Jia, G. Hua, B. Forbord, and J.K. Solberg: Mater. Sci. Eng. A, 2007, vol. A 444, pp. 284-90.

17. B.L. Ou, J.G. Yang, and M.Y. Wei: Metall. Mater. Trans. A, 2007, vol. $38 \mathrm{~A}$, pp. $1760-73$. 
18. J.D. Robson, M.J. Jones, and P.B. Prangnell: Acta Mater., 2003, vol. 51, pp. 1453-68.

19. J.D. Robson: Acta Mater., 2004, vol. 52, pp. 1409-21.

20. J.D. Robson: Acta Mater., 2004, vol. 52, pp. 4669-76.

21. O.N. Senkov, R.B. Bhat, S.V. Senkova, and J.D. Schloz: Metall. Mater. Trans. A, 2005, vol. 36(8), pp. 2115-26.

22. A. Jackson and T. Sheppard: Proc. 6th Int. Aluminum Extrusion Technology Conf., Chicago, Aluminum association, Washington DC, 1996, vol. 1, pp. 541-50.

23. X. Fan, D. Jiang, Q. Meng, and L. Zhong: Mater. Lett., 2006, vol. 60 , pp. $1475-79$.

24. R. Ciach and B. Dukiet-Zawadzka: J. Mater. Sci., 1978, vol. 13, pp. 2676-86.

25. B.D. Cullity, S.R. Stock, and S. Stock: Elements of X-Ray Diffraction, 3rd ed., Prentice Hall, 2001, pp. 351-55.

26. Alphabetical indexes for experimental patterns, Sets 1-52, International Center for Diffraction Data (ICDD), 2005, Powder Diffraction File Number (PDF no.) 01-071-4015.
27. M. Cooper: Acta Cryst., 1967, vol. 23, pp. 1106-07.

28. ASM Handbook, 10th ed., vol. 2, Non-Ferrous Alloys, ASM INTERNATIONAL, Metals Park, OH, 1992.

29. M. Dumont, W. Lefebvre, B. Doisneau-Cottignies, and A. Deschamps: Acta Mater., 2005, vol. 53, pp. 2881-92.

30. G. Sha and A. Cerezo: Acta Mater., 2004, vol. 52, pp. 4503-16.

31. A. Melander and P.A. Persson: Acta Metall., 1978, vol. 26, pp. $267-78$.

32. N.A. Belov, D.G. Eskin, and A.A. Aksenov: Multicomponent Phase Diagrams: Applications for Commercial Aluminum Alloys, Elsevier Science, New York, NY, 2005, pp. 1-46 and 191-22.

33. ASM Handbook, 10th ed., vol. 3, Alloy Phase Diagrams, ASM INTERNATIONAL, Metals Park, OH, 1992.

34. M. Conserva, E. Di Russo, and A. Giarda: J. Metall., 1973, vol. 6, pp. $367-72$.

35. E. Ho and G.C. Weatherly: Acta Metall., 1975, vol. 23, pp. 1451-60. 